\title{
Assessment of Quality of Primary Healthcare Facilities in West Bengal
}

\author{
Shatarupa Dey ${ }^{1 *}$, Shuvra Chattopadhyay ${ }^{2}$ \\ Assistant Professor, Dept. of Geography, Sarojini Naidu College for Women, India \\ Associate Professor, Dept of Geography, Lady Brabourne College, \\ India
}

*Corresponding Author: Shatarupa Dey, Assistant Professor, Dept. of Geography, Sarojini Naidu College for Women, India

\begin{abstract}
:
Aim: The present study aims to assess the extent of spatial and structural variation in quality of Primary Healthcare facilities in West Bengal.

Method: Using data from Health Management Information System, Govt. Of West Bengal, India, on availability of structural inputs for the year 2013-14in Primary Healthcare Centres (PHCs) from 341 Blocks, the district level Overall Development Index (ODI) is constructed. ODI is a composite measure of the relative importance of all available structural inputs in PHCs. A spatial variation of ODI is then depicted in map to present the shortfall of existence of structural inputs across different districts. To understand structural (domain-specific) variation and its inequality in PHCs, at the district level, Modified Overall Gini and IMR-based Concentration Index from Overall Development Indices (ODI) are used.

Results: The study reveals that inter-district variation in quality of healthcare across West Bengal ranges from 0.68 (Bankura) to 0.17 (Murshidabud). Domain-specific inequality is highest for laboratory facilities $(25.92 \%)$ and lowest for manpower (17.20\%). Moreover, the (IMR-based and MMR-based) Concentration Index, disease-based measure is used to present the inequality in the use of structural facilities at PHCs and show contrasting scenario with that of inequality in availability of Domain-specific facility. Here the inequality is highest for Services (29\%) for IMR and (32\%) for MMR while it is lowest for equipment facilities (6.5\%) for IMR and (3.13\%) for MMR.
\end{abstract}

Conclusion: Spatial variation of healthcare facilities as well as the Domain-specific inequality across the blocks as unit analysis from different districts are prominently distorting even under same flagship programme NRHM in West Bengal. Moreover there is huge gap between inequality in availability of facilities and inequality in use of facilities at PHCs in West Bengal. The present findings may help to review the health policies towards effective involvement of PHCs for wide intervention in primary healthcare facilities at District level in West Bengal.

Keywords: Primary healthcare centres, Overall Development Index, Modified Overall Gini, and IMR-based Concentration Index.

\section{INTRODUCTION}

India's public health owes its framework from the recommendations forwarded by Bhore Committee as far back as 1946.Bhore Committee headed by Joseph Bhore penned recommendations including formation of health committees with five to seven individuals in every village. This was largely ignored due to paucity of funds during pre-independence period.

Indian Government is trying to shape the formal national health mission to make plans and strategies to incorporate primary healthcare as a part of national health system and to sustain it, after the Alma Ata Declaration in 1978. WHO described the services provided by the primary healthcare system as 'essential healthcare' and thus it should be available and accessible to all (Park.K. 2009). Planning Commission's study reveals that piecemeal services in various primary health centres reduces the availability by manifold (Husain Z,2011).Negligence of primary care and primary healthcare institutions influenced the utilization of health services and worsened the epidemiological profile of 
the rural population in India(Nayar.R.K 2004). Indian Government emphasized the need of universal health coverage and launched the National Rural Health Mission in 2005 to revamp the public health system with special focus on primary healthcare institutions. The mission aims to achieve IMR of 30 per thousand live birth, maternal mortality of 100 per 100 thousand live birth and a total fertility rate of 2.1. To achieve these goals the core strategies of Rural Health Mission is to guarantee inter sectoral convergence, ensure health infrastructure including physical and human infrastructure, increase community participation, increase village level health workers, improve management inputs and ensure quality services (Asthekar.S, 2008). The recently developed policy proposal of India is visioning to achieve Universal Health Coverage by 2022(Planning Commission of India 2011).The three tier system of Primary healthcare in India shaped a formal breakthrough in the promotion of health service delivery for the common masses. After the National health policy in 1983 massive expansion of primary healthcare facilities through public health units is undertaken with the establishment of one PHC per 30,000 population and one Sub-centre per 5000(Gangolli.L et.al 2005). Planning commission recommended (2011) that primary healthcare units should account for maximum health expenditure reducing the need of secondary and tertiary medical facilities.

\subsection{Primary Healthcare in West Bengal}

After 1948, West Bengal Government started a scheme of ten bedded health centre at each Thana serving a population of 10000 and 100000 respectively. West Bengal is one of the earliest states to implement Primary health centres in a block with 3-5 subsidiary health centres for 60 to 80 thousand population. This scheme was initiated by Late Chief Minister DrB.C.Roy. According to the standard health plan (1952)of Planning Commission, it recommended to set up a 6 bedded health centre at each block and a 40 bedded health centre at the headquarter of each community Development(Ray. S. $\mathrm{K}$ et al 2011).

The State healthcare system is lacking because of utter deficiency in public health and managerial expertise in the Primary Healthcare for rural population and due to the existing gap between planning and implementation (K.Srinath Reddy2011). West Bengal's achievement in health outcome has been patchy and in some cases slow mainly due to the underfunding ( $0.8 \%$ of State GDP) of this sector (2004-13). The share of health in the State Budget is slightly reduced (4.38\% in 2006-07 to 4.30\% in 2010-11) (Report on West Bengal District Planning 2011). Hence, Primary healthcare system is nearly in the non-performing situation in front of the huge demand in rural areas. Thus, rural poor are bootstrapped with worse health condition along with the cycle of poverty. Department of Health and Family Welfare (DHFW), GoWB initiated the Health Sector Strategy (2004-2013) in tune with GOI tenth five year plan, National Health Policy and National Population Policy. One objective of this strategy is to ensure equity of coverage and quality at all levels of health and medical services delivery through an 'Essential Service Approach' for the next ten years (Report on Health Sector strategy 2004-13).

If we have an inner look in to the rural health care delivery situation, we can surely observe that the quality of healthcare is crippled by poor services, lack of manpower, higher rate of absenteeism of available health workers, lack of drugs and essential equipment's, poor quality of management practices and lot of other factors. There are only 909 Primary Health centres in West Bengal that are functioning out of 2166 PHC requirement. Out of 909 PHCs only 248 PHCs have beds according to the IPHC standards and rest of the PHCs cater only OPD services (RHS Bulletin 2012). There is the co-existence of governmental and non-formal non-governmental health services (absenteeism of structured private profit making agent) with different systems of medicine and ownership styles which includes non-profit institutions and for profit institutions. Earlier studies based on DLHS 3 data reveal that the lowest quality of care is found in West Bengal (Timothy et.al 2013). This gloomy nature of infrastructural facilities has paved the way for another informal network of healers (even without any proper training) like quacks, sales assistant in drug stores operating from home, grocery shops etc. (Sonam.K2002). People in West Bengal are witnessing a huge variation in healthcare service facilities across different population subgroups in terms of crucial services for the larger proportion of poor population. It is important for States to address the existing disparities in quality healthcare delivery given a specific goal that healthcare services should be 'universal'. In West Bengal little study has been done on the scenario of services provided to the people through primary healthcare units though they are perceived to be vital in achieving Universal Healthcare. 


\subsection{Research Gap}

Existing literature mainly focus on the prevailing regional disparity in distribution of primary health units, emphasizing the importance of 'number' of primary health units. Most health survey reports stress on population to health service unit ratio as an indicator of health facility achievement but as per Indian Public Health Standard (IPHC) West Bengal is far behind the target ratio. In quantitative terms even if the target ratio is achieved, there is no guarantee that the health facilities are effectively and efficiently used up by the population in the jurisdiction of health service unit. However the disparity in quality of services provided by primary health units is not much focussed. Moreover, the intra-domain disparity in the broader term 'health services' is not much addressed. Identification of domains that are lacking or progressing is difficult and yet not been addressed. Thus, present paper emphasizes on the study of extent of effective quality services provided by the PHCs.

\subsection{Objective of the Study}

To assess the distribution of effective and quality health service delivery among Districts in West Bengal, the present paper mainly focuses on the effective utilization of five domains of health services of PHCs like services, manpower, laboratory, physical infrastructure and equipment

Thus, the main objective of our study is:

- To highlight, how far the quality of health services in primary healthcare units varies spatially at district level, within West Bengal.

- To study the nature and extent of disparities in health care services across domain provided by the primary healthcare system.

- To study the contribution of the inter domain disparity of primary health units based on major health outcome i.e. Infant Mortality Rate and Maternal Mortality Rate are examined, as validation exercise of utilization of services in PHCs within the society.

\section{DATA AND METHODS}

Our Data has been gleaned from Facility Assessment Report of Health Information Management System (HMIS), Ministry of Health and Family Welfare, Government of West Bengal in 2012-2013. We have taken detailed information of the existing services provided by PHCs and on Infant Mortality Rate (IMR) in every blocks of West Bengal. Our quality of healthcare measure comprises indicators (selected relevant 43 indicators out of 53) on the availability of inputs essential for the functioning of PHCs as per as the Indian Public Health Standards. The services is categorised under five domains: availability of services, clinical staff in position; laboratory services; physical infrastructure; essential equipment and drugs. We have constructed a Deprivation Index of relative structural quality of care based on the composite measure comprising of various structural aspects of services of PHCs. The deprivation index of quality services at PHCs varies spatially within the blocks as well as districts of West Bengal. It indicates the extent to which the PHCs are incapable to perform up to the desirable standards (Table 1).The study is further extended to the domain-specific Decomposition analysis in order to obtain the contribution of each domain in overall calculated deprivation.

Table1. Indicators of Input Availability

\begin{tabular}{l} 
1. Services at PHCs \\
Out Patient Department (OPD), Emergency Services, Referral Services, In-Patient Services, Obstetric \\
Care, Antenatal Care, Intranatal Care, Post Natal Care, New - born Care, Care Including Immunization, \\
Family Planning. \\
\hline 2. Clinical staff in Position \\
Medical officer, Pharmacist, Nurse-mid wife, Health worker, Health educator, Health assistant, Clerks, \\
Laboratory Technicians, Drivers, AYUSH Practitioners. \\
\hline 3. Essential Laboratory Services \\
Routine urine, Stool and blood test, Blood Grouping, Diagnosis of RTI/STDS, Sputum test of TB, \\
Examination of Blood Smear (Malaria), Pregnancy Test, RPR Test, HIV Test. \\
\hline 4. Infrastructure \\
PHCs at Govt Building, Separate wards for male and female, Operation Theatre available, Labour room, \\
Reliable Water Source, waste Disposal and Availability of Electricity \\
5. Equipment \\
Availability of Equipment as prescribed list, Availability of drugs as per prescribed list, Furniture \\
availability, Two months' supply of essential drugs and Two months' supply of essential contraception. \\
\hline
\end{tabular}


[The basis of selection of each indicator are i) the 43 indicators make use of almost all available data in the report, restricting bias of selection of some indicators and leaving others. ii) All the indicators are according to Indian Public Health Standards and are meant to be available in PHCs and iii) all the five domains are mentioned in Alma Ata Declaration of 1978. Footnote 1]

\subsection{Deprivation Index}

$$
I_{i j}=\frac{\left(\operatorname{Max}_{i}-X_{i j}\right)}{\left(\operatorname{Max}_{i}-\operatorname{Min}_{i}\right)} \ldots \ldots \ldots \ldots . .1
$$

Where $\mathrm{I}_{\mathrm{ij}}$ indicates deprivation index of the $\mathrm{i}^{\text {th }}$ variable at $\mathrm{j}^{\text {th }}$ unit of study. $\operatorname{Max}_{\mathrm{i}}$ and $\operatorname{Min}_{\mathrm{i}}$ denotes maximum and minimum values of the $i^{\text {th }}$ variable in the series respectively. $X_{i j}$ denotes original value of the $i^{\text {th }}$ variable at $j^{\text {th }}$ unit of study. The value ranges from 0 (absence of deprivation) to 1(Highest deprived).

\subsection{Average Deprivation Index (A.D.I)}

$$
\text { A.D. } I\left(I_{j}\right)=\sum_{i=1}^{n} I_{j i} / n------------------------2
$$

Ij denotes the Index of Deprivation of jth unit of study

\subsection{Development Index}

Development index for the basic health facility achievement measured as

$$
\text { D. } I .=1-L_{j} D \ldots \ldots \ldots \ldots \ldots \ldots 3
$$

Where, $\mathrm{L}_{\mathrm{j}}$ is average deprivation index of $\mathrm{j}^{\text {th }}$ unit, value of D.I. $=1$ represents absence of disparity and 0 represents perfectly deprived.

\subsection{Inequality Analysis}

Addressing and understanding the need of an equitable and affordable primary healthcare only through the geographical variation in health service provision of PHCs will be halfhearted. It is imperative to understand the extent of inequality that exists among the five domains of primary healthcare facilities across all spatial regions (districts). It would be more insightful if the analysis focuses on finding the one spatial region laggard behind compare to other region. It is also urgent to pointing out the laggard domain for the vertical progression of equitable primary healthcare. For this, Inequality in Overall Deprivation (modified Gini, Wagstaff et.al 2003) is used to identify whether inequality in five domains exists across the spatial region. The value of Inequality in Overall Deprivation ranges from -1 to +1 .In case of absence of inequality the value is 0 .A negative value of Inequality in Overall Deprivation (modified Gini1997,Wagstaff et.al 2003) means inequality is higher among poor(Wagstaff et.al 2000). The Modified Overall Gini (M.O.G) can be written as

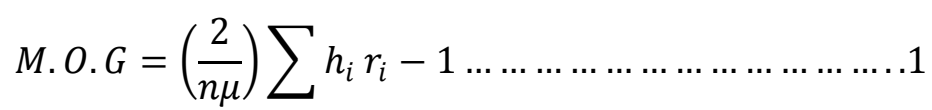

Here, $h_{i}$ is the health service variable, $\mu$ is the mean, $n$ is number of observation and $r_{i}=i / N$, which is the fractional rank of achievement scores of items at Block level of West Bengal.

The Mortality-Based Concentration Index (C.I) can be written as

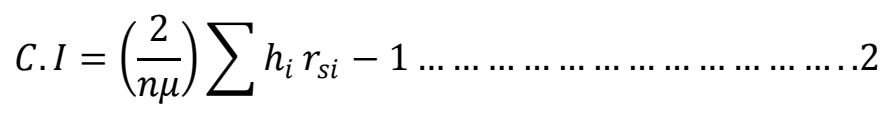

Here, $\mathrm{h}_{\mathrm{i}}$ is the health service facility variable, $\mu$ is the mean and $r_{s i}$ is the fractional rank of $\mathrm{h}_{\mathrm{i}}$ with respect to infant mortality status of Block level of West Bengal.

\subsection{Decomposition Analysis}

In order to explain the importance of sectoral composition of overall inequality in primary health services provided by the PHCs in different districts, the 'by component method' of decomposition (Clarke .P et al 2002)are to be analysed.The M.O.G can be decomposed (Clarke .P et al 2002) intothe inequalities between the service domains of PHCsby separating the contribution of five domains (s) of structural quality of health service. The analysis tries to find out the important service domain for which the overall inequality measure varies at highest degree (Phillip 2008).

The Modified Overall Gini (M.O.G) can be presented as weighted average of the Sectoral Gini (Clarke .P et al 2002) of the five domain(s) of health service on which it is based. 


$$
\begin{aligned}
& \text { M.O.G }=\sum W_{s} G_{S} \ldots \ldots \ldots \ldots \ldots \ldots \ldots \ldots \ldots
\end{aligned}
$$

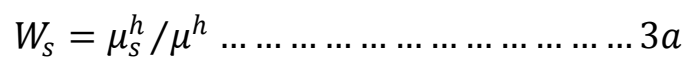

Here $\mu_{\mathrm{h}}$ is composed of five individual domain of health service delivery together. Let $G_{s}$ be the sectoral Gini for each service domain and $\mu_{s}^{\mathrm{h}}$ is mean of item score. Ws is the share the item represents of the total primary health service qualities by PHCs.

\section{RESUlTS AND ANALYSIS}

\subsection{Spatial Variation in Quality of Healthcare}

The effectiveness of primary health care facilities available at the PHC level varies in different extent and it is highly dependent on the availability of facilities and the geographical position of the PHCs in different districts of West Bengal. The value of deprivation of the availability and optimal use can give us the idea about the extent and position of different districts in terms of effective utilisation of quality primary health services. The deprivation index reveals the extent of deviation in quality of primary healthcare from the best performing district (Bankura) that varies spatially among different districts of West Bengal(Table 2). The value of deprivation of each district are normalised from 0 to 1 , where 0 means absence of deprivation and 1 is highest deprived. In terms of deprivation of quality health service, the districts are classified into four regions of very less deprived, less deprived, moderately deprived and highly deprived (Table 3).The classification of Districts echoes the spatial variation in quality of primary health care in five domains health care facilities respectively. The circle pointed area in maps show the least deprived district (blue colour circle) and the most deprived district (red colour circle) of West Bengal in each domain of primary health care.

Table2. District wise Average Deprivation Index

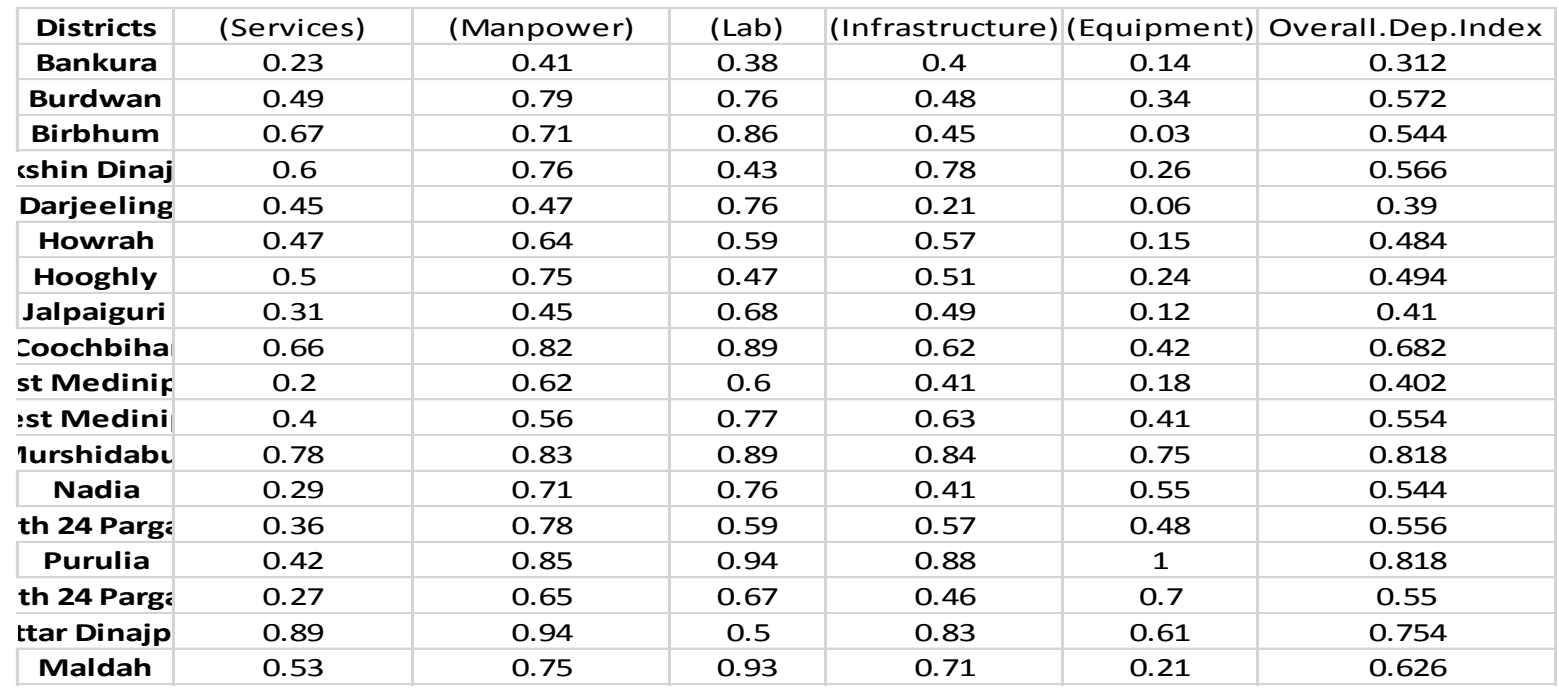

Table3. Classification of Districts based on Deprivation Index

\begin{tabular}{|c|c|c|c|c|c|}
\hline Domain & Services & Manpower & Laboratory & $\begin{array}{c}\text { Physical } \\
\text { Infrastructure }\end{array}$ & Equipment \\
\hline $\begin{array}{l}\text { VeryLess } \\
\text { Deprived }\end{array}$ & $\begin{array}{l}\text { Bankura,Medinipur, } \\
\text { Nadia, South } 24 \\
\text { Parganas,Jalpaiguri }\end{array}$ & $\begin{array}{c}\text { Darjeeling, } \\
\text { Jalpaiguri, } \\
\text { Bankura }\end{array}$ & $\begin{array}{l}\text { Bankura, Hooghly, } \\
\text { Uttar Dinajpur, } \\
\text { Dakshin Dinajpur }\end{array}$ & Darjeeling & $\begin{array}{c}\text { Bankura,Birbhum, } \\
\begin{array}{c}\text { Haora,Darjeeling,Ja } \\
\text { lpaiguri }\end{array} \\
\end{array}$ \\
\hline $\begin{array}{c}\text { Less } \\
\text { Deprived }\end{array}$ & North 24 Parganas & \begin{tabular}{|} 
Birbhum, Nadia, \\
Howrah, South 24 \\
Parganas, \\
Medinipur
\end{tabular} & $\begin{array}{c}\text { Jalpaiguri, Medinipur, } \\
\text { Haora, South } 24 \\
\text { Parganas, North } 24 \\
\text { Parganas. }\end{array}$ & $\begin{array}{c}\text { Jalpaiguri, Birbhum, } \\
\text { Bankura,Burdwan } \\
\text {,Nadia, Hooghly, } \\
\text { South 24 Parganas }\end{array}$ & $\begin{array}{l}\text { Dakshin Dinajpur, } \\
\text { Maldah, Burdwan, } \\
\text { Medinipur,Hooghly }\end{array}$ \\
\hline $\begin{array}{l}\text { Moderatel } \\
\text { y Deprived }\end{array}$ & $\begin{array}{c}\text { Purulia, Haora, } \\
\text { Hooghly, Burdwan, } \\
\text { Maldah, Darjeeling }\end{array}$ & $\begin{array}{c}\text { Dakshin Dinajpur, } \\
\text { Maldah, Burdwan, } \\
\text { Hooghly }\end{array}$ & $\begin{array}{l}\text { Darjeeling, Nadia, } \\
\text { Burdwan }\end{array}$ & \begin{tabular}{|c|} 
Koochbihar, \\
Medinipur, Howrah, \\
North 24 Parganas \\
\end{tabular} & $\begin{array}{l}\text { Nadia, North } 24 \\
\text { Parganas, } \\
\text { Koochbihar } \\
\end{array}$ \\
\hline $\begin{array}{c}\text { Highly } \\
\text { Deprived }\end{array}$ & $\begin{array}{c}\text { Birbhum, } \\
\text { Murshidabud, Uttar } \\
\text { Dinajpur,Dakshin } \\
\text { Dinajpur }\end{array}$ & $\begin{array}{c}\text { Purulia, } \\
\text { Murshidabud, } \\
\text { UttarDinajpur, } \\
\text { Koochbihar }\end{array}$ & $\begin{array}{l}\text { Birbhum, Purulia, } \\
\text { Murshidabud, } \\
\text { Maldah, Koochbihar }\end{array}$ & $\begin{array}{c}\text { Purulia, Murshida } \\
\text { bud, Maldah, Uttar } \\
\text { Dinajpur, Dakshin } \\
\text { Dinajpur }\end{array}$ & $\begin{array}{l}\text { South } 24 \text { Parganas, } \\
\text { Purulia, } \\
\text { Murshidabud, Uttar } \\
\text { Dinajpur }\end{array}$ \\
\hline
\end{tabular}




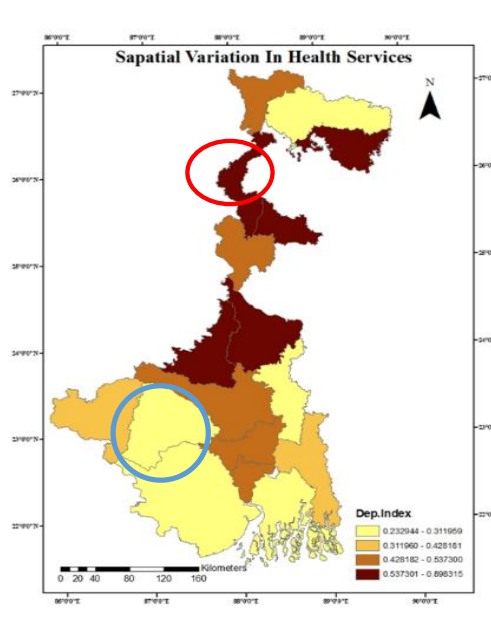

Fig 1

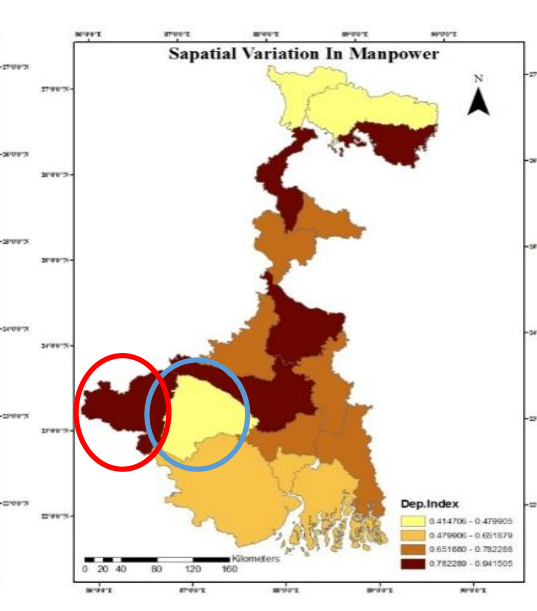

Fig 2

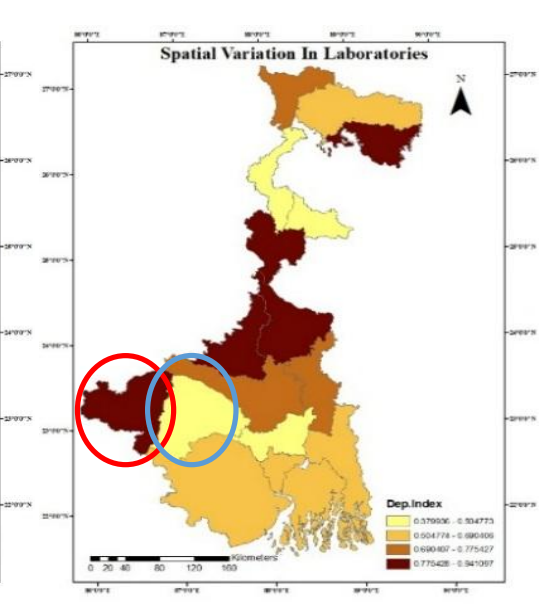

Fig 3

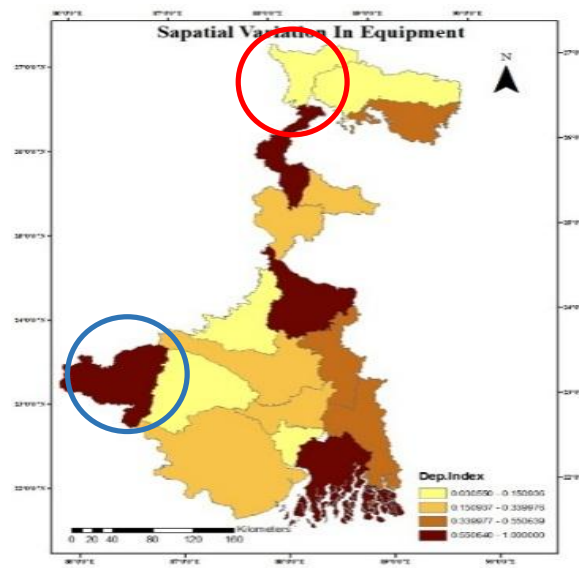

Fig 4

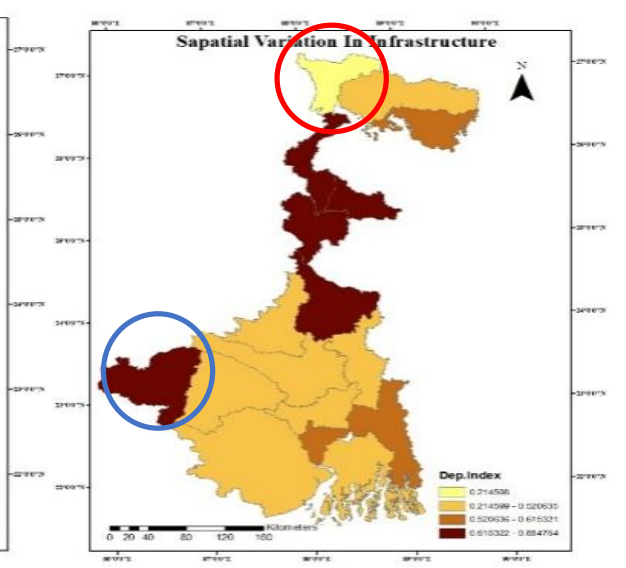

Fig 5

Indicates least deprived District, Indicates highest deprived District,

*This maps are for representation only and should not be used for identification of borders

Overall Development Index (table 4) reveals the summary index of overall development of quality of healthcare in West Bengal containing all five domains of health care facilities. There is wide distribution in quality of health care in different districts of West Bengal (Fig 6) implying the fact that the effective utilization of publicly provided health care facilities is sub-optimal. The distribution of inter district variation in quality of health care service across West Bengal is quiet annoying as it varies from a low of 0.17 to as high as 0.68. While Bankura (0.68), Darjeeling (0.60) and East Medinipur (0.56) are most developed in terms of the development index of quality of primary healthcare, lowest value of development index of quality healthcare is in Purulia (0.17) followed by Murshidabud (0.18). The other two less developed districts are Uttar Dinajpur and Koochbihar. Rest of the districts occupy moderately developed position ranging from 0.2 to 0.5 .

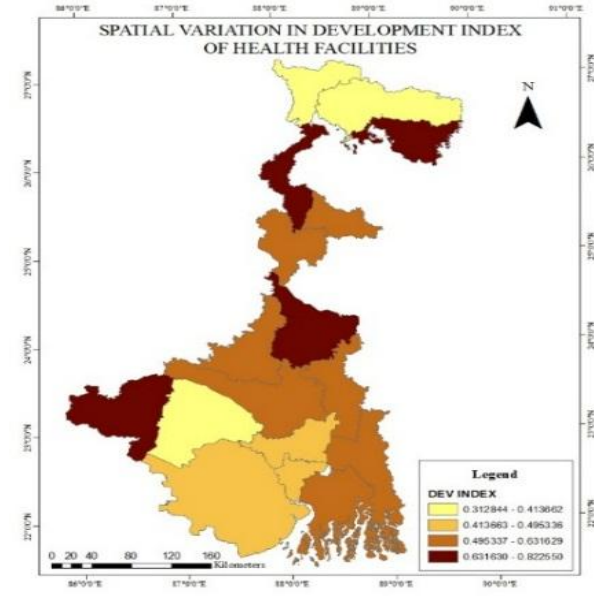

Fig 6

\begin{tabular}{|c|c|}
\hline Districts & Overall Development Index \\
Bankura & 0.680997662 \\
Darjeeling & 0.606225871 \\
East Medinipur & 0.56165245 \\
Jalpaiguri & 0.55859756 \\
Howrah & 0.512950487 \\
Hooghly & 0.504664033 \\
Birbhum & $\mathbf{0 . 4 5 6 6 3 4 5 4 5}$ \\
Nadia & 0.451111627 \\
South 24 & \\
Parganas & $\mathbf{0 . 4 4 8 9 6 2 0 8 3}$ \\
North 24 & $\mathbf{0 . 4 4 2 8 0 4 5 1}$ \\
Parganas & $\mathbf{0 . 4 4 1 6 8 0 8 0 9}$ \\
West Medinipur & \\
Dakshin & $\mathbf{0 . 4 3 2 8 2 5 9 1 7}$ \\
Dinajpur & $\mathbf{0 . 3 7 1 4 3 3 2 4 3}$ \\
Burdwan & $\mathbf{0 . 3 6 8 3 7 1 0 7 9}$ \\
Maldah & $\mathbf{0 . 3 1 7 7 0 9 4 2 4}$ \\
Coochbihar & $\mathbf{0 . 2 4 3 1 5 6 2 7 5}$ \\
Uttar Dinajpur & $\mathbf{0 . 1 8 0 5 4 9 3 3 4}$ \\
Murshidabud & $\mathbf{0 . 1 7 7 4 4 9 5 1 8}$ \\
Purulia & \\
\hline
\end{tabular}

Table 4 


\subsection{Inter Domain Disparity in Healthcare Facility}

Disparity in primary healthcare is both spatial and structural. After finding the spatial disparities among districts, it is important to examine the domain specific structural inequality analysis to show the extent of performance each domain kipping in mind the fact that the absolute difference of structure is realised on the basis of the region specific need. Thus, the present section of the analysis deals with the theme that how domains of primary healthcare facilities are contributing within the overall inequality. The identification of comparatively weak domains is thus the first and foremost task and thus the Overall Structural Deprivation are measured to understand health-service related inequality by using Overall Modified Gini (M.O.G) (Clarke .P et al 2002).

The overall inequality M.O.G) containing all (five healthcare services) considering all of 341 blocks in West Bengal is high (0.18). This is due to the fact that all PHCs are not actively providing services in all five domains. As one PHC is better in some domain and very poor in other domains then overall performance may not be bad. Thus, the present analysis is extent to the inequality analysis of primary health facilities provided by the PHCs, with respect to each domain. The disaggregated picture for domain specific inequality gives the interesting result.

The Modified Gini (MO.G) of primary healthcare facilities, by domain, is illustrated in the following table (5). The positive value of modified Gini implies facility density for any specific domain is less than the requirement of density of PHCs and it is aggravating with more and more number of densities of PHCs.

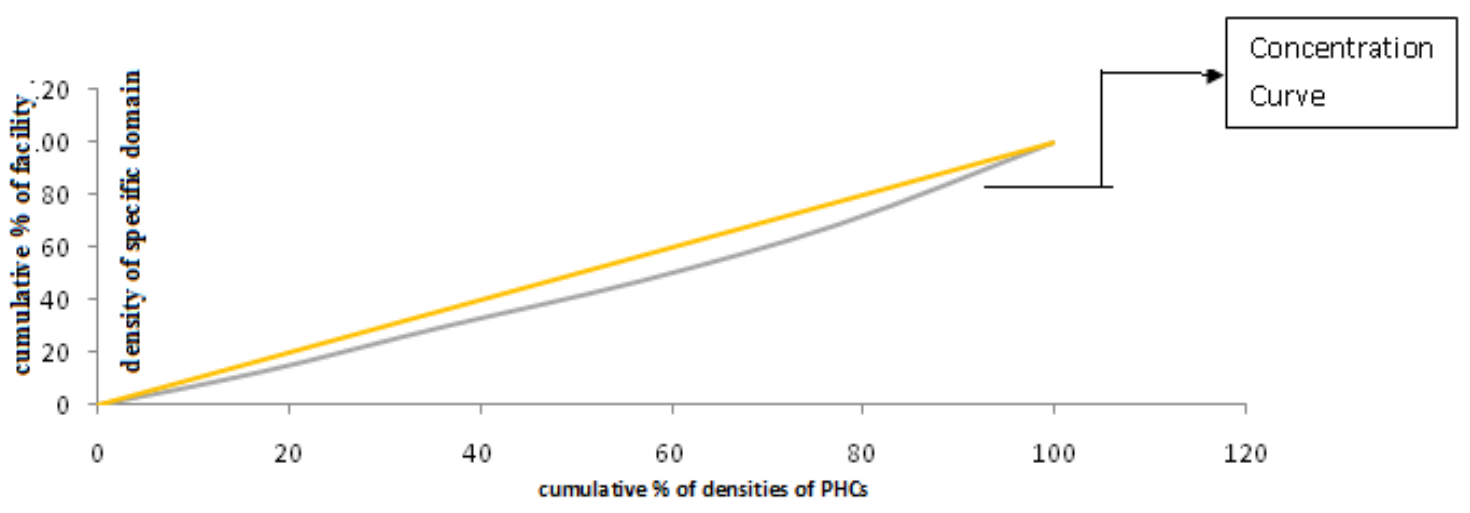

Fig 7

Moreover, higher the value of M.O.G implies PHCs are more catastrophic in nature in terms of service provided for a specific domain. In our analysis the Modified Overall Gini (equation 1) ranges from 0.575 for equipment to 0.27 for manpower. The contribution of each domain $\left(W_{s} G_{s}\right)$ in overall inequality is the weighted average of domain specific M.O.G (Clarke .P et al 2002), where weights are nothing but the share of domain specific deprivation value divided by total deprivation value $\left(W_{s}=\mu_{s}^{h} / \mu^{h}\right)$. The higher the value of contribution implies that this specific healthcare facility domain is performing badly compared to other domain and vice-versa. It is evident that not all domains contribute equally. Among PHCs in West Bengal laboratory services contribute highest to the overall inequality (26\%). Service contributes(20\%) second, equipment(19\%) third and manpower and physical infrastructure each contribute (17\%).The intuition behind the percentage contribution is that if there is no inequality in terms of laboratory services facility the overall inequality will reduce by $25 \%$.From the analysis it is thus unambiguously evident that laboratory and service facilities needs great attention from the reallocation or redistribution point of view to reduce inequality in primary healthcare facilities in PHCs level.(Table 5, Fig 8)

Table5. Domain specific Contribution in Overall Inequality in Primary Healthcare Facilities

\begin{tabular}{|c|c|c|c|c|}
\hline Domain & O.M.G & ws & Sectoral Contribution & \% Contribution \\
\hline Services & 0.47 & 0.17 & 0.08 & 20.34 \\
\hline Manpower & 0.27 & 0.24 & 0.06 & 17.20 \\
\hline Lab & 0.41 & 0.24 & 0.10 & 25.92 \\
\hline Infrastructure & 0.34 & 0.20 & 0.06 & 17.46 \\
\hline Equipment & 0.57 & 0.13 & 0.07 & 19.06 \\
\hline Overall & 0.18 & & 0.39 & 100 \\
\hline
\end{tabular}




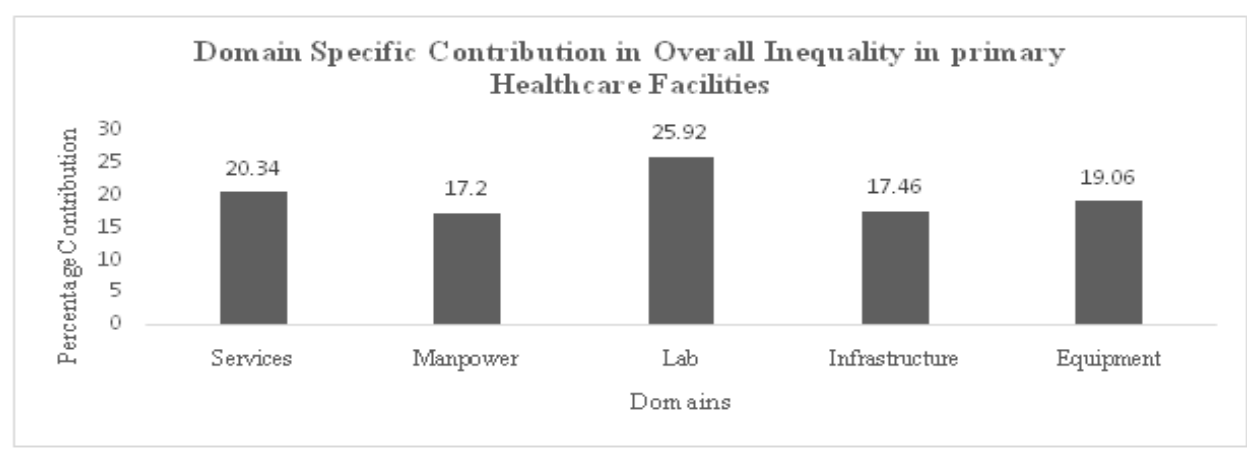

Fig 8

\subsection{Healthcare Facilities and Health Outcome}

After getting the domain wise contribution in overall inequality in primary health care facilities, the obvious query is to ask how the inequality in these domains of primary health care facilities go hand in hand with the inequality in disease or mortality based demand. The purpose of this extension is to assess the actualisation of the effects through the relationship of supply of primary health care facilities with that of the required need as pursued by health outcome indicators. For that the correlation coefficient of health mortality outcome (Infant Death, Maternal Death) with Average Deprivation Index of healthcare facilities suggest that correlation coefficient between only deprivation of healthcare facilities at primary level and child and maternal death is not very trivial. The result (Table 6) shows that the deprivation of laboratories is correlated with child death which is significant at $10 \%$ Confidence level. The result is important as the contribution of laboratory facilities is highest(26\%) at PHCs in Overall inequality. Thus more deprivation of laboratory facilities at PHCs can increase child death.

Table6. Correlation between Healthcare Facilities and Health Outcome

\begin{tabular}{|l|l|l|l|l|l|}
\hline & $\begin{array}{l}\text { Avg.Dip.Index } \\
\text { (service) }\end{array}$ & $\begin{array}{l}\text { Avg.Dip.Index } \\
\text { (Manpower) }\end{array}$ & $\begin{array}{l}\text { Avg.Dip.Index } \\
\text { (lab) }\end{array}$ & $\begin{array}{l}\text { Avg.Dip.Index } \\
\text { (physical infrastructure) }\end{array}$ & $\begin{array}{l}\text { Avg.Dip.Index } \\
\text { equipment) }\end{array}$ \\
\hline child death & 0.3775 & 0.355 & $0.4167^{*}$ & 0.2697 & 0.2603 \\
\hline maternal death & 0.2919 & 0.3674 & 0.2806 & 0.2147 & 0.3416 \\
\hline
\end{tabular}

Significant at $* \mathrm{p}<0.10$

\subsection{Inequality in Health Outcome based Healthcare Facility}

The urgency of health facilities provided by PHCs for the ends of the marginal and poor population is utmost. These facilities can assure the people to come out from disease and mortality conditions. Hence, the present analysis is extent further to mortality based inequality analysis for PHC provided healthcare facilities in West Bengal. In the first step thus the analysis shows how infant mortality rate (IMR) based Concentration Index contributes to Overall Modified Gini of healthcare service (Equation 2 and table 7, Fig 9). IMR based C.I contributes 50\% of the overall inequality, given other numerous factors that determine the inequality in pattern of utilization of PHC provided services. Thus, Overall Modified Gini can be $50 \%$ lower in absence of inequality in healthcare facilities used for IMR. The picture is quite different in domain specific analysis. In case of health service facility domain only 33\% of O.M.G can be explained by IMR based Concentration Index. It is positive for all domains which imply the fact that the utilization of existing facilities in all domains at PHC level are lower for the Blocks in which IMR is comparatively high. Manpower is contributing29 \%, physical infrastructure $28 \%$, lab $19 \%$ and equipment $8 \%$ of O.M.G respectively. MMR based C.I contributes $42 \%$ of the overall inequality. Overall Modified Gini can be $43 \%$ lesser in absence of inequality in healthcare facilities used for MMR. (Table 8, Fig 10)

Table7. Domain Specific Contribution of IMR based Concentration Index to Overall Inequality in Healthcare Facilities.

\begin{tabular}{|l|l|l|c|}
\hline Domain & IMR based C.I & O.M.G & CI \% of O.M.G \\
\hline Services & 0.1556 & 0.4720 & 32.97 \\
\hline Manpower & 0.0792 & 0.2745 & 28.88 \\
\hline Lab & 0.0807 & 0.4150 & 19.44 \\
\hline Infrastructure & 0.0949 & 0.3408 & 27.85 \\
\hline Equipment & 0.0452 & 0.5753 & 7.87 \\
\hline Overall & 0.0913 & 0.1816 & 50.32 \\
\hline
\end{tabular}

Source: Computed by the authors 


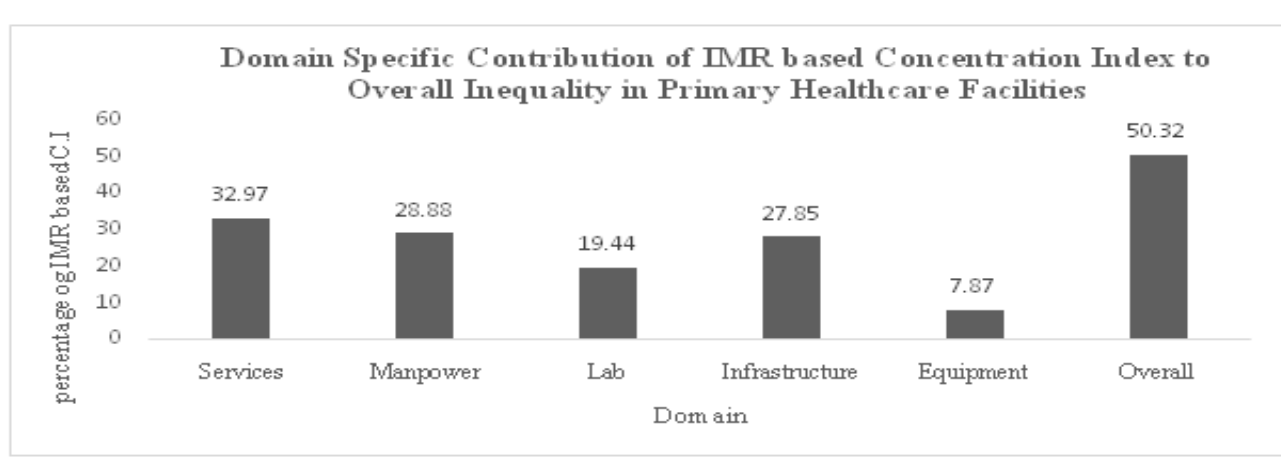

Fig 9

Table8. Domain Specific Contribution of MMR based Concentration Index to Overall Inequality in Healthcare Facilities

\begin{tabular}{|l|c|c|c|}
\hline \multicolumn{1}{|c|}{ Domain } & MMR based C.I & O.M.G & CI \% of O.M.G \\
\hline Services & 0.1450 & 0.4720 & 30.73 \\
\hline Manpower & 0.0759 & 0.2745 & 27.65 \\
\hline Lab & 0.0643 & 0.4150 & 15.50 \\
\hline Infrastructure & 0.0741 & 0.3408 & 21.75 \\
\hline Equipment & 0.01835 & 0.5753 & 3.19 \\
\hline Overall & 0.07694 & 0.1816 & 42.36 \\
\hline
\end{tabular}

Source: Computed by the authors

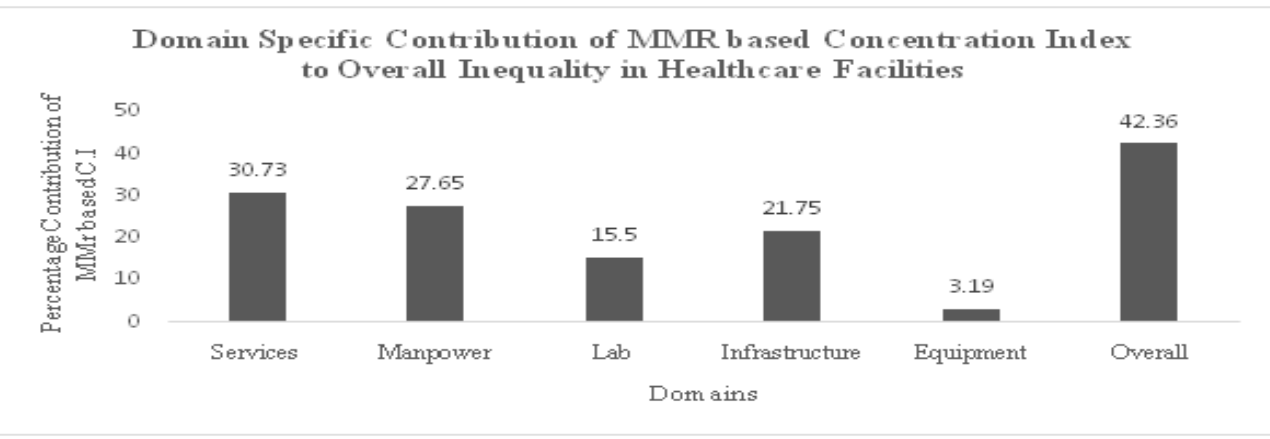

Fig 10

\subsection{Decomposition of Domain-Specific Contribution Inequality in IMR based Healthcare Facility}

In separating the percentage contribution (ws CIs) of five domains in IMR based C.I; the picture is quite complex spiral of relative strength of each domain. Among PHCs in West Bengal, equipment contribute lowest to the IMR based Concentration Index (6.5\%). Manpower, laboratory and physical infrastructure contributes equally i.e. (21\%) and services contribute highest (29\%) (Table9,Fig11).Thus, from the analysis it is evident that primary health service facilities need highest priority in West Bengal in terms of infant mortality based inequality analysis. In MMR based C.I similar result is observed. Equipment contribute lowest to MMR based Concentration Index (3.13). Physical infrastructure contributes second lowest ((19.5\%), laboratory third (20.6\%), manpower forth (24.48) and service facilities contribute highest (32.16\%) (Table10, Fig12).Therefore, the picture shows completely opposite scenario in availability of primary health facility and actual (mortalitybased at least partially by IMR and MMR; one can do the same with other mortality indicator or together) use of primary health facility if and when required.

Table9. Domain Specific Contribution of IMR based Concentration Index to Overall Inequality in Healthcare Facilities

\begin{tabular}{|c|c|c|c|c|}
\hline Domain & IMR Based C.I & ws & Sectoral Contribution & \% Contribution \\
\hline Services & 0.15 & 0.17 & 0.03 & 29.06058 \\
\hline Manpower & 0.07 & 0.24 & 0.02 & 21.52878 \\
\hline Lab & 0.08 & 0.24 & 0.02 & 21.83746 \\
\hline Infrastructure & 0.09 & 0.20 & 0.02 & 21.07159 \\
\hline Equipment & 0.04 & 0.13 & 0.01 & 6.501584 \\
\hline Overall & 0.09 & & 0.09 & 100 \\
\hline
\end{tabular}

Source: Computed by the authors 


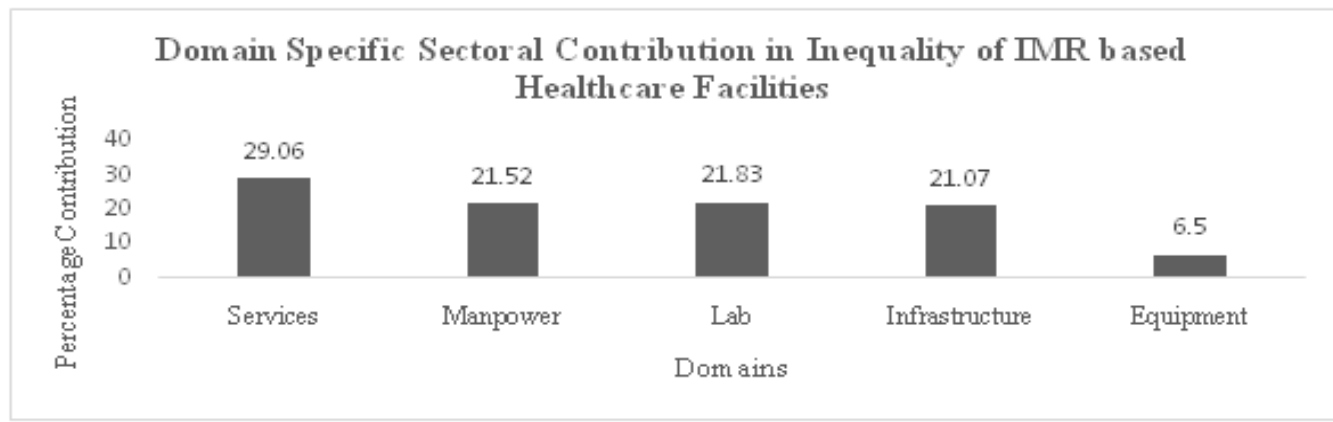

Fig 11

Table10. Domain Specific Contribution of MMR based Concentration Index to Overall Inequality in Healthcare Facilities

\begin{tabular}{|c|c|c|c|c|}
\hline Domain & MMR Based C.I & ws & Sectoral Contribution & \% Contribution \\
\hline Services & 0.1450 & 0.17 & 0.1237 & 32.16 \\
\hline Manpower & 0.0759 & 0.24 & 0.0941 & 24.48 \\
\hline Lab & 0.0643 & 0.24 & 0.0795 & 20.67 \\
\hline infrastructure & 0.0741 & 0.20 & 0.0751 & 19.54 \\
\hline equipment & 0.0183 & 0.13 & 0.0120 & 3.13 \\
\hline overall & 0.0769 & & 0.3847 & 100 \\
\hline
\end{tabular}

Source: Computed by the authors

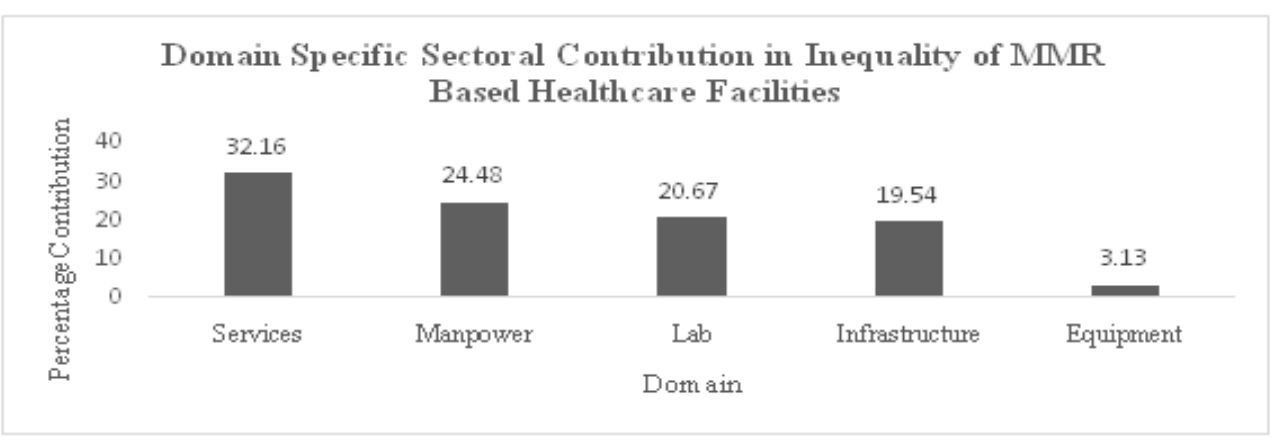

Fig 12

\section{CONCLUDing REMARKS}

The National Rural Health Mission is a flagship scheme launched in 2005 to perform necessary architectural correction in the primary healthcare delivery System (Sinha .A, 2009). In this regard, this study shows that primary healthcare system in West Bengal is lagging behind in some regions and in some domains. All the districts in West Bengal are not performing similarly even under one flagship programme. The Districts of Purulia and Murshidabud is barely functioning compared to IPHC standards. This is astonishing because entire state comes under the same policy and similar funding decision yet their spatial disparity in primary healthcare is still persistent. Thus minimizing geographical variation in healthcare is an ardent need.

The variation in contribution of each of the five domains show that although the services, physical infrastructure and equipment are hoisted but architectural correction in domains like laboratories and manpower is required to make primary healthcare effective and available to people particularly poor, women and children. The picture shows completely opposite scenario in availability of primary health facility and actual (mortality-based) use of primary health facility if and when required. Thus, the huge gap between the availability and use can only be explained by the actual effectiveness of the available primary healthcare facilities in PHC level of West Bengal. That is why the reliability on publicly provided health facility is going down day by day and the out of pocket expenditure of the poor common mass is increasing. As a result the shifting of population from APL category to BPL category is increasing due to the huge health expenditure for common health hazard of the population in West Bengal. Therefore, it is important to analyse and understand the need-based utilization of primary health services according to the socio-economic structure of the population under different PHCs. 
Even we are far from commitment of 'Universal Health Coverage' addressing the geographical and structural gaps, the policy planners should concentrate in the correction of anomalies that arises in between the availability and use of the primary healthcare facilities in PHC level in effective way, so that optimum use of limited resources can be ensured at least in favour of the poorer section of population.

Identification of comparatively weak domains within the preview of PHCs will help planners and policy makers to suggest the strong intervention on urgent basis.

\section{REFERENCES}

[1] Ashtekar.S (2008): "The National rural Health mission: A Stocktaking", Economic and Political weekly, XLIII (37):23-26.

[2] Balarajan,Y,S. Selvaraj and S V Subramanian(2011): "Health Care and Equity in India", Lancet, 377(9764):505-15

[3] Bhattacharya P.K, "Do West Bengal and Other Provinces in India Need Reforming for a poor-friendly, safe, quality and effective healthcare system instead of a Health industry, public-private partnership, or health tourism for the Rich and middle Class society of The State or Country?"Annals of Tropical Medicine and Public Health, 6:(269-73)

[4] Clarke P, Smith L, JekinsonC(2002): "Comparing health inequalities among men aged 18-65 years in Australia and England using the SF-36," Austr New Zealand Journal Public health,26(136-143).

[5] Gangolli.L, Duggal.R, Shukla.A (2005): Review of Healthcare in India, CEHAT.

[6] Gerdtham U-G, Johannesson M(2001): "Income -Related Inequality in Life Years and Quality-Adjusted Life Years", Journal Health Economics, 19:1007-1026

[7] Husain.Z (2011): "Health of the National Rural health Mission", Economic and Political Weekly, XLVI (4): 53-60

[8] Nayar. K.R (2004): "Rural Health: Absence of Mission or Vision"? Economic and Political Weekly :( 4872-4874).

[9] Patil.A.V, Somasundaram and R C Gopal(2002): "Current Health Scenario in Rural India", Australian Journal of Rural Health,10(2):129-35

[10] Park.K (2009),'Preventive and Social Medicine', 12th edition, BanarasidasBhanotPublishers,India :29-30

[11] Planning Commission of India (2011): High Level Expert Group Report on Universal Health Coverage for India, Government of India, New Delhi.

[12] Reddy, K S, V Patel, P Jha, V K Paul, A K Kumar, L Dandona and H Lancet India Group (2011): "Towards Achievement of Universal Healthcare in India by 2020: A Call to Action", Lancet, 377(9767):760-68.

[13] Sinha.A (2009): “In Defence of National Rural Health Mission”, Economic and Political Weekly, XLIV (14): $72-76$

[14] Timothy P, Jackson, Acharya A, Mills A(2013): “ An Assessment of the Quality of Primary Healthcare in India", Economic and Political Weekly, 13(9):53-58.

[15] Van Doorslaer E, Wagstaff A, BleichrodtH:(1997) “ Income related inequality in health some international Comparisons", Journal of Health Economics ,16:93-112.

[16] Wagstaff.A (2000): "Socio-economic Inequalities in Child Mortality: Comparisons Across Nine Developing Countries", Bulletin of the World Health Organisation 2000, (78): 19-29.

[17] Wagstaff. A, van Doorslaer.E : "Overall versus Socio-economic Health Inequality: A Measurement Framework and Two Empirical Illustrations. Health Economic Lett 2003

[18] http://www.wbhealth.gov.in/annual_report/2010-11.pdf

[19] http://www.wbhealth.gov.in/health sector/strategy.pdf

[20] http://www.wbhealth.gov.in/health sector/strategy2004-13.pdf

\section{AUTHOR's BIOGRAPHY}

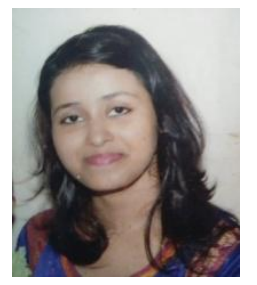

Shatarupa Dey. Assistant Professor in Dept of Geography, Sarojini Naidu College for Women, Interest Area is Human Geography, Development Studies and Health Issues. Research Associate in ICSSSR Major Project 


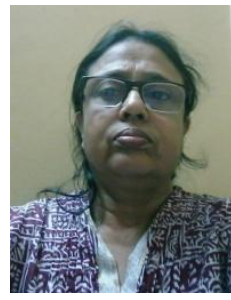

Dr Subhra Chattopadhyay - Associate Professor in Dept of Geography, Lady Brabourne College, Interest Area is Regional Planning, Agricultural Studies and Geomorphology. Supervisor of six Doctoral Scholar

Citation: Shatarupa Dey, Shuvra Chattopadhyay. "Assessment of Quality of Primary Healthcare Facilities in West Bengal". International Journal of Research in Geography. vol 4, no. 2, 2018, pp. 22-33. doi:http://dx.doi.org/ 10.20431/2454-8685.0402003.

Copyright: (c) 2018 Authors. This is an open-access article distributed under the terms of the Creative Commons Attribution License, which permits unrestricted use, distribution, and reproduction in any medium, provided the original author and source are credited. 